\title{
Preoperative Gabapentin Dosage Relationship to Length of Stay in Post-Anesthesia Care Unit in Patients Undergoing Pelvic and Breast Surgery
}

\author{
Jonia Alshiek ${ }^{1,2}$, Sara Hamade ${ }^{1}$, Jennifer A. R. Vaz ${ }^{1}$, S. Abbas Shobeiri1 ${ }^{*}$ \\ ${ }^{1}$ Inova Fairfax Women's Hospital, Falls Church, VA, USA \\ ${ }^{2}$ Department of Obstetrics and Gynecology, Hillel Yafe Hospital, Hadera, Israel \\ Email: *Mark.Sobczynski@inova.org
}

How to cite this paper: Alshiek, J., Hamade, S., Vaz, J.A.R. and Shobeiri, S.A. (2021) Preoperative Gabapentin Dosage Relationship to Length of Stay in Post-Anesthesia Care Unit in Patients Undergoing Pelvic and Breast Surgery. Open Journal of Obstetrics and Gynecology, 11, 1843-1850. https://doi.org/10.4236/ojog.2021.1112171

Received: October 7, 2021

Accepted: December 27, 2021

Published: December 30, 2021

Copyright $\odot 2021$ by author(s) and Scientific Research Publishing Inc. This work is licensed under the Creative Commons Attribution International License (CC BY 4.0).

http://creativecommons.org/licenses/by/4.0/

\begin{abstract}
Background: Gabapentin is routinely prescribed preoperatively to decrease postoperative pain intensity. It is included in the enhanced recovery after surgery (ERAS) recommendations. Objective: To analyze correlation of gabapentin dosage and post anesthesia care unit (PACU) length of stay (LOS) and cost. Study Design: A retrospective chart review of patients who underwent general anesthesia and received preoperative oral gabapentin from June 2017 to August 2017 for pelvic and breast procedures. The main outcome was correlation between PACU LOS and gabapentin dosage in the outpatients. Financial analysis was performed to assess the cost to the hospital associated with increased LOS. Results: Of the 636 patients, 405 patients received 300 $\mathrm{mg}$ and 231 patients received $100 \mathrm{mg}$ gabapentin. Mean dosage per $\mathrm{kg}$ $(\mathrm{mg} / \mathrm{kg} \pm \mathrm{SD}$ ) was $3.12 \pm 1.51$ (range: 0.86 to 6.12 ). PACU LOS was $96 \pm 77$ (minutes \pm SD) in patients receiving $100 \mathrm{mg}$ and $120 \pm 96$ in patients receiving $300 \mathrm{mg}$ capsule $(\mathrm{p}=0.001)$. Linear regression analysis, failed to show a statistically significant correlation between per kg dosage and PACU LOS $(p=0.13)$. Using multiple regression analysis, we calculated the correlation coefficient to be +1.71 minutes per $1 \mathrm{mg} / \mathrm{kg}$ gabapentin (95\% CI: -3.75 to $+7.10, \mathrm{p}=0.54)$ after adjusting for confounders. Adding $3 \mathrm{mg} / \mathrm{kg}$ to pre-op gabapentin dosage of all outpatients cost on average, an extra $\$ 9794$ per month in this cohort. Conclusion: Every $1 \mathrm{mg} / \mathrm{kg}$ increase in gabapentin dosage adds an estimated 7.1 minutes to PACU LOS. A $3 \mathrm{mg} / \mathrm{kg}$ increase in gabapentin adds estimated 22 additional minutes in PACU LOS. Unfortunately, increase LOS is associated with increased hospital costs.
\end{abstract}




\section{Keywords}

Gabapentin, Enhanced Recovery after Surgery, Post Anesthesia Care Unit, Length of Stay

\section{Introduction}

Gabapentin is an anti-epileptic drug utilized in postoperative pain management since 2002. It conveys its effects through $\alpha 2 \delta$-subunits of voltage-gated calcium channels, causing a decrease in excitatory neurotransmitters and leading to anti-hyperalgesia effects [1]. The use of gabapentin in gynecologic and breast surgeries is encouraged in Enhanced Recovery After Surgery (ERAS)-based approaches [2]. Despite lack of evidence, surgeons avoid high dose preoperative gabapentin fearing increased sedation and dizziness [1] [3] [4]. This study assessed the impact of high-dose preoperative gabapentin in all patients who received preoperative gabapentin for their gynecologic and breast procedures in our facility in three months. Our primary endpoint was a correlation between gabapentin dosage and Post Anesthesia Care Unit (PACU) length of stay (LOS) in outpatients. PACU LOS was chosen not simply for its cost but also as an indicator of gabapentin adverse effects that result in delayed PACU discharge [5]. To ensure the reliability of the results, we also analyzed the data of all patients before excluding inpatients. The secondary aim of this study was to define costs associated with the increased PACU LOS to aid health systems in cost-conscious value-based decision-making.

\section{Materials and Methods}

This retrospective study was approved by the institutional review board (IRB) of INOVA Fairfax Hospital, Falls Church, Virginia, USA. We used the Epic medical records system to gather data from the computerized files of gynecology patients who A) underwent general anesthesia and B) received preoperative oral gabapentin from June 1, 2017 to August 31, 2017. The outpatient stay was defined as Medicare's definition of fewer than 24 hours stay in the facility [6], and they were analyzed both with inpatients and separately to assess selection bias. Patient demographics, American Society of Anesthesiologists (ASA) score, procedure type, and duration were recorded. For analysis, procedures were divided into minimally invasive surgeries versus others and hysterectomies versus others. Prescribed gabapentin dosage was divided by patient weight to calculate per kilogram dosage $(\mathrm{mg} / \mathrm{kg})$. The primary outcome was a correlation of PACU LOS to gabapentin dosage per kg.

Institutional cost accounting data for outpatient surgery was evaluated and compared to available cost estimation models available for PACU LOS. The first hour of outpatient PACU stay is estimated to cost $\$ 591$ [7]. In most hospitals, one minute of PACU stay costs $\$ 8$ to $\$ 10$ (average \$9) [7] [8]. Based on institu- 
tional cost accounting principles, the PACU LOS was further divided into inpatient and outpatient. At our institution, the costs are reported based on timedriven activity-based costing standards across the industry [9].

All statistical analyses were performed using Stata/IC version 14.2 (StataCorp LLC, Texas). After ensuring data normality, a One-sided t-test or Pearson-chi ${ }^{2}$ analyses were used for independent variables. Regression analyses were used to assess the primary outcome. Possible confounding effects of patient age, BMI, procedure duration, procedure type, and American Society of Anesthesiologists (ASA) score were adjusted using multiple regression analysis to assess PACU LOS. A 95\% confidence interval (CI) was applied, and a p-value of less than .05 was considered statistically significant. To prove non-inferiority, we specified a clinically acceptable delta of maximum 30 minutes increase in PACU LOS given the favorable analgesic effect of gabapentin. Based on preliminary data on PACU LOS in the hospital, we calculated a standard deviation of 90 minutes in PACU LOS. We calculated that 155 patients per group would have $90 \%$ power to detect a 30 minutes difference between the groups. Therefore, we reviewed all gynecology surgical patient charts in three months to cover this amount of patients.

\section{Results}

A total of 775 patient charts were reviewed. The median age was 51 , and the mean age was $51.5 \pm$ 13.7. Details of the procedures are illustrated in Table 1. Overall, 512 patients (66\%) received $300 \mathrm{mg}$ gabapentin and 263 patients (34\%) received $100 \mathrm{mg}$ gabapentin (all Neurontin). Median and mean per kg dosage $(\mathrm{mg} / \mathrm{kg})$ were 3.32 and $3.33 \pm 1.49$, respectively (range: 0.89 to 6.12 ). PACU LOS was $100 \pm 77$ (minutes $\pm \mathrm{SD}$ ) in patients receiving $100 \mathrm{mg}$ and $120 \pm 90$ in patients receiving $300 \mathrm{mg}$ dosages (one-sided t-test: $\mathrm{p}=0.001$ ). However, per $\mathrm{kg}$ dosage was not significantly correlated with PACU LOS in simple linear regression analysis (correlation coefficient $[C C]=2.54, r^{2}=0.002, \mathrm{p}=0.23$ ).

Factors affecting gabapentin dosage: Patients were more likely to receive 300 $\mathrm{mg}$ gabapentin if they were undergoing hysterectomy $(83 \%$ vs. $57 \%, \mathrm{p}<0.001)$, minimally invasive surgery ( $77 \%$ vs. $56 \%, \mathrm{p}<0.001$ ) (Table 1 ), or if they were African American $(\mathrm{p}<0.001)$. They were also more likely to be inpatients $(73.6 \%$ vs. $63.9 \%, \mathrm{p}=0.018)$. Patients who received the $300 \mathrm{mg}$ dosage were younger ( 48.8 vs. $56.8, \mathrm{p}<0.001$ ) and more obese (BMI 29.2 vs. $27.5, \mathrm{p}=0.001$ ). Patients' gabapentin dosage did not significantly differ in terms of procedure duration ( $\mathrm{p}$ $=0.080)$, or ASA score $(\mathrm{p}=0.64)($ Table 2$)$.

In our multiple regression model, we adjusted PACU LOS to the effects of $\mathrm{BMI}$, procedure duration, age, ASA score, and procedure type. The primary outcome (per kg association with PACU LOS) was assessed after the adjustments: Gabapentin dosage was not significantly correlated with PACU LOS ( $\mathrm{p}=$ 0.38 ). After adjusting to the mentioned variables, the calculated correlation coefficient was +2.12 minutes per every $1 \mathrm{mg} / \mathrm{kg}$ increase in gabapentin dosage $(95 \%$ CI: $-2.57-+6.80$ ). Furthermore, hysterectomy patients had borderline higher 
Table 1. Procedures and percentage of patients receiving $100 \mathrm{mg}$ vs $300 \mathrm{mg}$ gabapentin capsule.

\begin{tabular}{ccccc}
\hline \multirow{2}{*}{ Procedure category } & $\mathbf{1 0 0 ~ \mathbf { ~ m }}$ & $\mathbf{3 0 0 ~ \mathbf { ~ g }}$ & \multirow{2}{*}{ Total } \\
\cline { 2 - 3 } & $\mathbf{N}(\%)$ & $\mathbf{N}(\%)$ & \\
\hline Abdominal hysterectomy & $3(5)$ & $54(95)$ & 57 \\
Breast procedures* & $121(73)$ & $44(27)$ & 165 \\
Hysteroscopy \pm biopsy & $6(35)$ & $11(65)$ & 17 \\
MI (not hysterectomy) & $29(23)$ & $95(77)$ & 124 \\
MI hysterectomy & $45(20)$ & $179(80)$ & 224 \\
Laparotomy & $7(18)$ & $32(82)$ & 39 \\
Other^ & $31(35)$ & $58(65)$ & 89 \\
Vaginal hysterectomy & $3(25)$ & $9(75)$ & 12 \\
& & Pearson Chi ${ }^{2}$ & $p$ Value $<0.001$ \\
\hline
\end{tabular}

*Mastectomy, lumpectomy, breast biopsy; MI: Minimally Invasive; ^Lymph node dissection, vulvar surgeries, Transvaginal Tape insertion.

Table 2. One-sided t-test analysis of all patients who received $100 \mathrm{mg}$ vs $300 \mathrm{mg}$ gabapentin.

\begin{tabular}{cccc}
\hline & $100 \mathrm{mg}$ & $300 \mathrm{mg}$ & p Value \\
\cline { 2 - 3 } & Mean \pm SD $(95 \% \mathrm{CI})$ & Mean \pm SD $(95 \% \mathrm{CI})$ & \\
\hline Per kg & $1.47 \pm 0.36(1.43-1.52)$ & $4.08 \pm 1.01(3.99-4.17)$ & $<0.001$ \\
BMI & $27.5 \pm 6.7(26.7-28.31)$ & $29.2 \pm 7.6(28.5-29.9)$ & 0.001 \\
$\begin{array}{c}\text { PACU duration } \\
\text { (min) }\end{array}$ & $101 \pm 77(91-110)$ & $120 \pm 90(112-128)$ & 0.001 \\
$\begin{array}{c}\text { Inpatient duration } \\
\text { (hour) }\end{array}$ & $71.3 \pm 86.1(45.7-96.9)$ & $73.9 \pm 80.1(59.9-87.9)$ & 0.428 \\
Age & $56.8 \pm 14.8(55.0-58.6)$ & $48.8 \pm 12.2(47.7-49.9)$ & $<0.001$ \\
$\begin{array}{c}\text { Procedure duration } \\
\text { (min) }\end{array}$ & $97 \pm 66(89-106)$ & $104 \pm 62(99-110)$ & 0.080 \\
ASA & $2.2 \pm 0.6(2.1-2.2)$ & $2.2 \pm 0.6(2.2-2.3)$ & 0.184 \\
\hline
\end{tabular}

PACU LOS $(C C=+14.0, p=0.050)$ when adjusted for other variables. Patients who underwent minimally invasive surgery were significantly more likely to have higher PACU LOS $(C C=+29.2, \mathrm{p}=0.001)$ when adjusted for other variables. Patients with an ASA score of four also had substantially higher PACU LOS after adjusting for other variables $(\mathrm{CC}=98.7, \mathrm{p}<0.001)$. Age, BMI, and procedure duration were not significantly associated with PACU LOS $(p=0.60,0.157$, 0.171 ; respectively).

After excluding inpatients, 636 outpatients remained. In the outpatients, 405 (64\%) received $300 \mathrm{mg}$ and 231 (36\%) received $100 \mathrm{mg}$ gabapentin. Mean dosage per $\mathrm{kg}(\mathrm{mg} / \mathrm{kg} \pm \mathrm{SD})$ was $3.12 \pm 1.51$ (range: 0.86 to 6.12 ). PACU LOS was $96 \pm$ 
77 (minutes $\pm \mathrm{SD}$ ) in patients receiving $100 \mathrm{mg}$ and $120 \pm 96$ in patients receiving $300 \mathrm{mg}$ capsules (One-sided t-test: $\mathrm{p}=0.001$ ). Simple linear regression analysis failed to show a statistically significant correlation between per $\mathrm{kg}$ dosage and PACU LOS $\left(\mathrm{CC}=+3.62, r^{2}=0.002, \mathrm{p}=0.13\right)$. Results of the outpatient multiple regression analysis were similar to the previous model: per $\mathrm{kg}$, the dosage was not significantly correlated with PACU LOS; we calculated the correlation coefficient to be +1.71 minutes per $1 \mathrm{mg} / \mathrm{kg}$ increase in gabapentin dosage (95\% CI: -3.75 to $+7.10, \mathrm{p}=0.54)$ after adjusting for BMI, procedure duration, age, ASA score, and procedure type. Furthermore, hysterectomy patients had borderline higher PACU LOS after adjusting for other variables $(\mathrm{CC}=+17.6, \mathrm{p}=$ 0.054 ). Patients who underwent minimally invasive surgery were significantly more likely to have higher PACU LOS after adjusting to other variables $(\mathrm{CC}=$ $+30.5, \mathrm{p}=0.001)$. Patients with an ASA score of 4 had borderline significantly higher PACU LOS $(\mathrm{CC}=89.9, \mathrm{p}=0.050)$. Age, BMI, and procedure duration were not significantly associated with PACU LOS $(\mathrm{p}=0.79,0.163,0.119$, respectively).

Cost analysis: Average extra per person cost of increasing pre-op gabapentin dosage by $3 \mathrm{mg} / \mathrm{kg}$ (provided overall dose $<6 \mathrm{mg} / \mathrm{kg}$ ) was calculated to be $1.71 \times$ $3 \times \$ 9=\$ 46.2$. The maximum per person cost was estimated to be $7.1 \times 3 \times \$ 10=$ \$213. In three months period, our hospital had 636 patients (average 258 per month). For the hospital, adding $3 \mathrm{mg} / \mathrm{kg}$ to the pre-op gabapentin dosage of all outpatients would cost on average an extra $\$ 9794$ per month.

\section{Structured Discussion/Comments}

Principal Findings: In this study, we used PACU LOS as an indicator of the overall positive and negative effects of preoperative gabapentin administration as part of ERAS protocol in outpatient pelvic and breast surgery patients. Patients in the PACU are carefully monitored for vital signs, nausea, vomiting, signs of bleeding, level of consciousness, and pain intensity. These patients are unlikely to be discharged if they have significant adverse events. After accounting for confounding factors, we have safely presumed that length of PACU stay is a good indicator of short-term surgical adverse events such as pain, nausea, and vomiting [5].

Results: According to our calculation, every $1 \mathrm{mg} / \mathrm{kg}$ increase in dosage adds an additional 7.1 minutes to PACU LOS, which means a $3 \mathrm{mg} / \mathrm{kg}$ increase in dose of gabapentin adds an estimated additional 22 minutes PACU LOS.

Clinical implications: We have concluded that adding $3 \mathrm{mg} / \mathrm{kg}$ for the overall dosage of $<6 \mathrm{mg} / \mathrm{kg}$ is unlikely to have statistically significant adverse effects in the short period following surgery. This finding should encourage surgeons to consider utilizing the higher dose of gabapentin to their ERAS utilization in the preoperative phase.

Research Implications: Additionally, future studies should include creating algorithms to assist surgeons in deciding to use higher versus lower doses of ga- 
bapentin to ensure safe practices to assist in same-day surgeries. Proposals for future research should include creating electronic documentation to better track patient progress in the PACU to analyze barriers to same-day discharge for patients scheduled to have outpatient procedures.

Strengths and Limitations: There are several weaknesses in our study. If we presume that any patient showing significant adverse effects to gabapentin will most likely be admitted as an inpatient for observation, excluding inpatients may lead to selection bias. To assess for such bias, we performed a thorough analysis of all patients before excluding the inpatients to determine for a significant difference. Our calculations did not show any significant difference between the two analyses. We believe it is safe to assume that this bias was not present in our study. We did not include other medications prescribed to each patient. It is possible that patients who received higher doses of gabapentin also received different doses of other medications to decrease the adverse effects of gabapentin (e.g., decreased pre-op benzodiazepine). Or those patients received lesser of drugs that have a similar positive effect of gabapentin (e.g., anti-emetics).

This was a retrospective study, and patients were not randomized. The procedures' duration and PACU lengths of stay were recorded for routine hospital record-keeping and not for the specific reason of this research. Furthermore, data for pain intensity and scale was not available in our dataset. There are studies in the literature that adding gabapentin to a multimodal pain regimen does not reduce acute pain, opioid consumption, or chronic pain after surgery [10]. An optimal dose of gabapentin for various gynecologic surgeries has not been established. There is limited data in other disciplines about the optimal dose of gabapentin for a specific surgery [11]. In a study of minor gynecological procedures involving hysterectomy, single preoperative dose of $100 \mathrm{mg}$ pregabalin did not reduce acute pain or improved recovery [12]. Preoperative oral gabapentin and acetaminophen prior to abdominal and vaginal hysterectomies, in addition to intravenous dexamethasone, has been shown to be ineffective for decreasing opioid consumption [13]. Another publication, showed that total dose of opiates administered in PACU was lower in patients on the standardized laparoscopic hysterectomy multimodal pathway, demonstrating better post-operative pain control. Mean PACU fentanyl dose fell from $49.17 \mathrm{mcg}$ to $24.19 \mathrm{mcg}$ with use of the pathway; median went from 25 to 0 mcg [14]. Studies on enhanced recovery after gynecologic surgery are limited but seem to have similar outcome benefits to populations who have had colorectal surgery [15]. Despite mixed literature on the utility of gabapentin for postoperative pain, it is generally established that gabapentin decreases post-op pain intensity. As such, participants in a cost-effectiveness study should be assessed for pain intensity for an accurate conclusion. There are other considerations besides pain for gabapentin usage. For example, a $600 \mathrm{mg}$ of gabapentin two hours before diagnostic gynecological laparoscopy has been shown to decrease the frequency and severity of postoperative nausea and vomiting [16]. 
Average increase in cost for extra $3 \mathrm{mg} / \mathrm{kg}$ gabapentin was calculated to be about $\$ 46$ per person in our hospital. Since the PACU to floor transfer is initiated only when the patient has an acceptable pain level, the higher dose of gabapentin and associated increased length of stay does not confer any additional benefits to the patient. The annual estimated cost savings to switch to lower dose gabapentin in this group of patients undergoing outpatient surgeries in our hospital is $\$ 120,000$. Six thousand gynecologic surgeries awere performed at our hospital, but the analysis was performed for a fraction $\left(1 / 10^{\text {th }}\right)$ of these surgeries.

\section{Conclusion}

Deciding to lower gabapentin dosage to decrease hospital costs largely depends on the hospital costs and budget. Based on the current analysis at our hospital, we have calibrated our processes for this group of patients to receive the lower dose of gabapentin. In conclusion, this study highlights the fact that although the difference in some medical interventions may not show statistical significance, the financial considerations should be taken into account during continued process improvement in a value-based cost-conscious environment.

\section{Authors' Contribution}

All authors contributed to the literature search, drafted the manuscript, provided review of manuscript, figures, and revised the manuscript. All authors critically reviewed, edited, and approved the final manuscript for publication.

\section{Conflicts of Interest}

The authors whose names are listed immediately below certify that they have NO affiliations with or involvement in any organization or entity with any financial interest (such as honoraria; educational grants; participation in speakers' bureaus; membership, employment, consultancies, stock ownership, or other equity interest; and expert testimony or patent-licensing arrangements), or nonfinancial interest (such as personal or professional relationships, affiliations, knowledge or beliefs) in the subject matter or materials discussed in this manuscript.

\section{References}

[1] Fabritius, M.L., Geisler, A., Petersen, P.L., Wetterslev, J., Mathiesen, O. and Dahl, J.B. (2017) Gabapentin in Procedure-Specific Postoperative Pain ManagementPreplanned Subgroup Analyses from a Systematic Review with Meta-Analyses and Trial Sequential Analyses. BMC Anesthesiology, 17, Article No. 85. https://doi.org/10.1186/s12871-017-0373-8

[2] Kalogera, E. and Dowdy, S.C. (2016) Enhanced Recovery Pathway in Gynecologic Surgery: Improving Outcomes through Evidence-Based Medicine. Obstetrics and Gynecology Clinics of North America, 43, 551-573. https://doi.org/10.1016/j.ogc.2016.04.006

[3] Grant, M.C., Lee, H., Page, A.J., Hobson, D., Wick, E. and Wu, C.L. (2016) The Effect of Preoperative Gabapentin on Postoperative Nausea and Vomiting: A Meta-Analysis. Anesthesia \& Analgesia, 122, 976-985. 
https://doi.org/10.1213/ANE.0000000000001120

[4] Han, C., Kuang, M.J., Ma, J.X. and Ma, X.L. (2017) The Efficacy of Preoperative Gabapentin in Spinal Surgery: A Meta-Analysis of Randomized Controlled Trials. Pain Physician, 20, 649-661. https://doi.org/10.36076/ppj/2017.7.649

[5] Ganter, M.T., Blumenthal, S., Dübendorfer, S., Brunnschweiler, S., Hofer, T., Klaghofer, R., et al. (2014) The Length of Stay in the Post-Anaesthesia Care Unit Correlates with Pain Intensity, Nausea and Vomiting on Arrival. Perioperative Medicine, 3, Article No. 10. https://doi.org/10.1186/s13741-014-0010-8

[6] Centers for Medicare \& Medicaid Services (2012) Expansion of Medicare Telehealth Services for CY 2013. Pub 100-02 Medicare Benefit Policy, CMS Manual System. Transmittal, 167.

[7] Hamid, H., Nwachukwu, B., Moon, D., Usoro, A., Stubbs, A. and Freehill, M. (2015) Cost Minimization Analysis of Post Anesthesia Care Unit (PACU) Recovery versus Short Stay Hospital Admission for Outpatients Procedures. American Othopedic Foot and Ankle Society, Rosemont.

[8] Dyrda, L. (2017) 101 ASC Benchmarks to Know. Becker's ASC Review. https://www.beckersasc.com/101-asc-benchmarks-to-know-2017.html

[9] Porter, M.E. and Teisberg, E.O. (2006) Redefining Health Care: Creating ValueBased Competition on Results. Harvard Business Press, Boston.

[10] Clarke, H., Pereira, S., Kennedy, D., Andrion, J., Mitsakakis, N., Gollish, J., et al. (2009) Adding Gabapentin to a Multimodal Regimen Does Not Reduce Acute Pain, Opioid Consumption or Chronic Pain after Total Hip Arthroplasty. Acta Anaesthesiologica Scandinavica, 53, 1073-1083. https://doi.org/10.1111/j.1399-6576.2009.02039.x

[11] Pandey, C.K., Navkar, D.V., Giri, P.J, Raza, M., Behari, S., Singh, R., et al. (2005) Evaluation of the Optimal Preemptive Dose of Gabapentin for Postoperative Pain Relief after Lumbar Diskectomy: A Randomized, Double-Blind, Placebo-Controlled Study. Journal of Neurosurgical Anesthesiology, 17, 65-68. https://doi.org/10.1097/01.ana.0000151407.62650.51

[12] Paech, M.J., Goy, R., Chua, S., Scott, K., Christmas, T. and Doherty, D.A. (2007) A Randomized, Placebo-Controlled Trial of Preoperative Oral Pregabalin for Postoperative Pain Relief after Minor Gynecological Surgery. Anesthesia \& Analgesia, 105, 1449-1453. https://doi.org/10.1213/01.ane.0000286227.13306.d7

[13] Bauchat, J.R., Milad, M.P., Kolb, S., Hilao, J. and McCarthy, R.J. (2017) Effects of Preoperatively Administered Oral Gabapentin and Acetaminophen on Opioid Consumption When Added to an Analgesic Regimen Containing Dexamethasone for Abdominal and Vaginal Hysterectomies. Journal of Gynecologic Surgery, 33, 243 247. https://doi.org/10.1089/gyn.2017.0052

[14] Mikdachi, H.S., Mihalov, L. and Makhija, N. (2016) Decreased Postoperative Opiate Use Following Implementation of a Multimodal Perioperative Medication Pathway [12Q]. Obstetrics \& Gynecology, 127, 142S. https://doi.org/10.1097/01.AOG.0000483571.46927.84

[15] Bauchat, J.R. and Habib, A.S. (2015) Evidence-Based Anesthesia for Major Gynecologic surgery. Anesthesiology Clinics, 33, 173-207.

[16] Khan, M.A., Siddiqi, K.J. and Khan, M.S. (2017) Prophylactic Use of Gabapentin to Reduce Postoperative Nausea and Vomiting in Patients Undergoing Diagnostic Gynecological Laparoscopy. Anaesthesia, Pain \& Intensive Care, 21, 19-24.

[17] Torbé, E., Crawford, R., Nordin, A. and Acheson, N. (2013) Enhanced Recovery in Gynaecology (Scientific Impact Paper No. 36). Royal College of Obstetricians and Gynaecologists, London. 